\title{
Craters: Between cleared and constructed, between absent and present
}

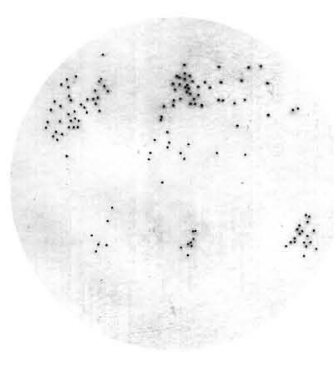

Fig. 1 Author (2016). Craters [Drawing]
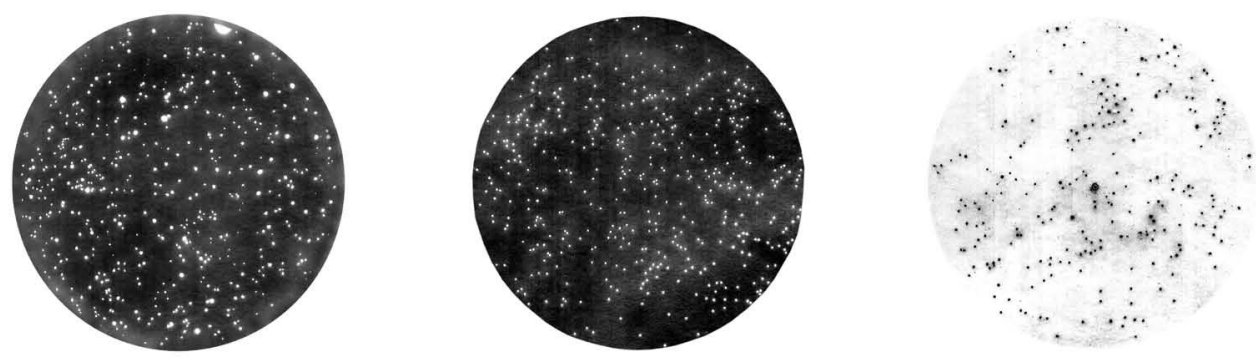

The following piece is a bricolage of both absence and presence, borne of the observation of such synchronous phenomena within a 1953 exhibition, held at the Institute of Contemporary Arts, London, called Parallel of Life and Art. This exhibition, edited by the Independent Group, presented a constellation of photographic figures; reproductions of scientific and artistic origins, lifted from an array of publications, were scattered at different scales around the surfaces (walls, ceiling and floor) of the gallery (Henderson, Paolozzi, Smithson and Smithson: 1953). There were no captions. Only an accompanying catalogue detailing the titles and sources of each image, though not all references were able to be cross-referenced with the (mis/un)numbered images, if indeed they were present. The exhibition's organisers called themselves 'The Editors'. One of the Editors, the photographer Nigel Henderson, documented the final installation through a series of photographs. It is in the space between two of these photographs that one may notice a subtle difference: one ${ }^{*}$ of the suspended images is in one photograph absent, and in the other present.

What seems significant is that this absent-present image was an aerial view of a crater. Captured by J. R. Eyerman and distributed through Life Magazine (Lichtenstein and Schregenberger, 2001: 44), it was found by the Parallel of Life and Art exhibition's Editors, who selected it as part of their spatialisation of the scrapbooks of images which they used to pass between one another (Henderson, ,=1953: unpag.). The following piece does not focus on the exhibition itself (there is undoubtedly much more to explore), nor on the specific photograph of the crater and its photographer; it does not question why the image (dis)appeared, nor 
what it may have represented to the exhibition's Editors. Rather, it deconstructs and re-textualises the spatial phenomena associated with the word crater, tracing the understandings and associations of these at once both forcibly evident and evasive marks, joining the dots and translating between spatial and textual fields much as the tales of the stars in the sky try to comprehend our origins through narrative.

This piece is an opening; an opening outward toward the peripheral, the marginal, and from the crater image to the craterous landscape of post-World War II London, in which the Parallel of Life and Art exhibition took place. It is a series of productive readings about the site of the exhibition and the sites from which it borrows. Yet, it is also a tracing through etymological origins and mythological tales whose beginnings, like the exhibition itself, are only allusive references, tales passed down through the generations, deflecting ad infinitum.

There are two voices differentiated in what follows, and each rests respectively in sites of absence (cleared) and of presence (constructed). This has been reflected in formatting, as well as in referencing styles. In the first voice, the formatting and style reflect that of the exhibition: scattered, with spaces between, and with an accompanying catalogue of references, not inserted in the midst of the writing but, rather, separate. The second, meanwhile, allows for a more conventional reading, a grounded counterbalance to the more allusive character of the other half of its pairing.

In the first pairing, I focus on origins, the background of the initial image from the exhibition and the sources of the notions of the 'clear' and 'constructed' site which have so profoundly affected my considerations of what 'site' is and can be. In the second, I move from the ground to the sky, and from what is tangible to what remains beyond reach. I transition from the constellations, a crater beyond our orbit, to other, interconnected points of reference beyond the knowable parameters of a site conventionally delineated by its boundaries, its outlines on a map. In the third, in light of the division between clear and constructed, the absent-present is accommodated with a discussion of the crater as 'trace', as writing, before following with a fourth pair that offers a manifestation of these ideas, opening the sieve-like post-war cityscape to a tracing of its inheritance and context. Finally, the last pairing returns the crater to the textual realm and to the beginning; to the nature of the crater as between cleared and constructed, and between absent and present.

These dialogues are a frame to the figures; they are the contexts and conversations which constellate around these particular definitions and associations of craters, though they are by no means exclusive. The three-dimensional figures allude to the crater image of the exhibition in their placement. All were traced by hand, on trace, before being reproduced, layered, then photographed once more, as were all of the figures within Parallel of Life and Art. Each is at once both a clearing, and a construction: a plot of simultaneous craters, all at different scales from the ground to the universe to the city. The black and white markings play with perceptions of what is absent and what is present, while the layering of traces enables a glimpse into the space between. 
Fig. 2 Author (2016). Meteor Crater, with trace overlay of all known craters on Earth [Drawing]

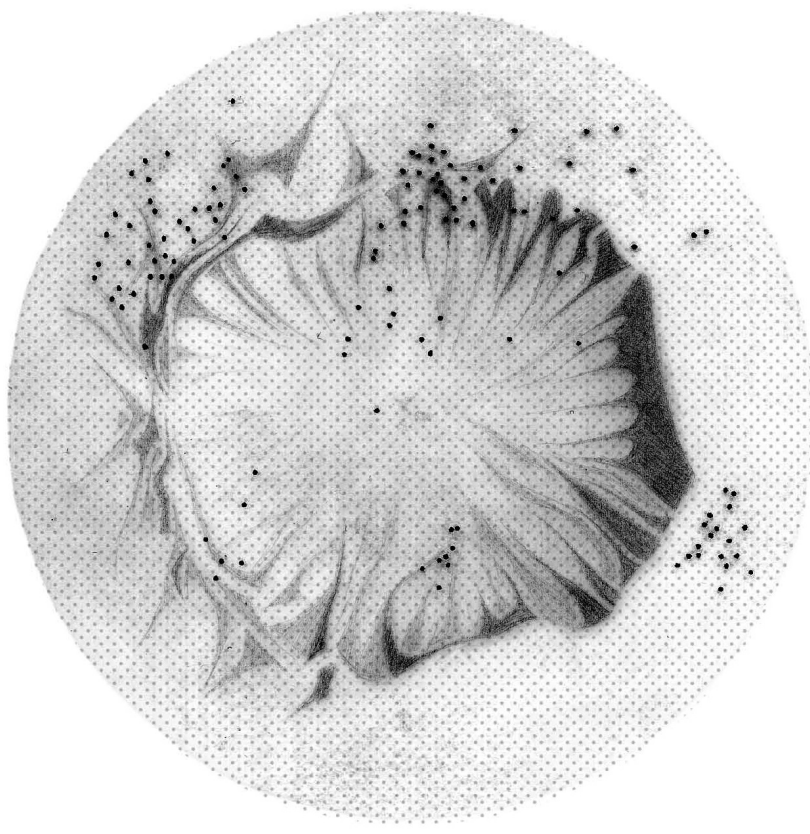

\section{[to explore the interstices] ${ }^{* *}$}

\author{
$I$.
}

The figure is an image of a CRATER.

\section{A reproduction.}

This CRATER may be found somewhere within the desolate landscape of Arizona, as well as captured and enclosed within scrapbooks of images, scattered across sites often unknown and uncharted:

\section{imaginary museums.}

It has been known by many names, including 'Meteor Crater', and an aerial photograph of this hollowed field was included in Life Magazine in the late 1940s and 1950s, at a time when its meteoritic origins were still uncertain.

Though, in the early 1900s, tunnels were drilled, and compasses held, nothing was discovered beneath the surface of the hole; no hidden iron deposit shifted the direction of the needle. Fragments of meteoritic iron were only to be found scattered across and within the surface surrounding the crater's rim. Yet, further into the century, studies appeared to indicate (fittingly for NASA, whose Apollo training programme was later undertaken there) that this CRATER was caused by the impact of a meteorite, a foreign object

from outside the atmospheric margins

of

the

Earth's spinning

sphere. 


\title{
[the gaps and fractures]
}

\author{
II.
}

The text 'On Site: Architectural Preoccupations' (Burns 1991), opens with a drawing for James Turrell's volcanic art project of Roden Crater, Arizona. The place of the human race within the context of the universe has for centuries been derived from the sky, gazing upward toward the unknown. Yet, it is a crater that the artist first saw from the air, looking down on the clearing below (Adcock and Turrell, 1990: 154; 158, 196). Turrell has spoken of his captivation of spaces devoid of function, and buildings 'emptied of their use'. Alongside the drawing for the crater project within Burns' text appeared the following quote:

In mythic origins, the first human place was the sky, made by Jove's thunder and lightning. To see it more clearly, the primeval forest was cleared; the clearings or 'eyes', loci, became groves as centres for ritual. ... The place-making rituals and geometry of the clearing were later transformed to foundation rites. ... The first mythic clearings established the site both as the embodiment of the sacred and as the source of human culture. (Burns, 1991: 146)

The crater marks a clearing-be it volcanic, meteoritic or man-made. Although they are each different causes of cavities within the spatial environment, all simultaneously destroy and create. All value the silence of the space between. A small piece of sky; a column of unbreathed air (Colomina, 2004). Perhaps we arrived here from elsewhere, perhaps our source-our origin-lies both within the clearings of the Earth and the abyss within which it floats. Findings are perpetual: the footnotes will never stop. Yet, it is still wonderful to wonder if we are all made of stars.

Fig. 3 Author (2016). Crater constellation, with trace overlay of the unknown abyss between stars [Drawing]

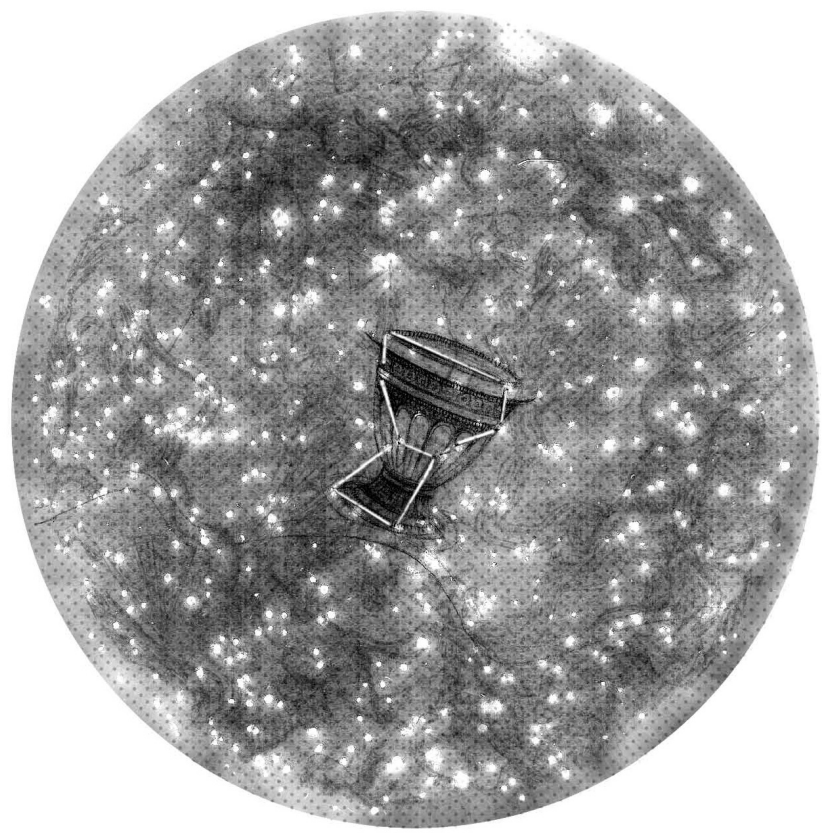




\title{
[the spaces between]
}

\author{
$I$.
}

The word

\section{CRATER}

is also a name for one of the constellations.

Greek for 'cup', it is identified with Apollo, and associated with the Greek mythological tale in which Apollo sends a crow to fetch water, who, after resting, finally returned with a snake as an excuse. But Apollo was wise to the crow's idleness, and saw through the deception, casting all three-cup, crow, and snake-into the heavens.

Finding figures in the skies, joining the brightest dots, may be seen as a form of pareidolia: where visual significance is perceived in what would otherwise be random stimuli, a predilection which predates writing. The constellations, including Crater, all form a path through the darkness; the shimmering dots are ellipses

suspended within the blank page,

the emptiness,

hoping to be drawn together by the human imagination.

The astronomical and astrological signs are actually out of sync with one other, a phenomenon known as precession. The sun occupies Ophiuchus for part of its cycle, yet, there is no astrological sign for Ophiuchus.

To the Greeks he was known as Asclepius. Amongst many other myths, he was the Son of Apollo and Coronis, an unfaithful wife. A crow brought Apollo the grim news but instead of being honoured was cursed, and is thus found immortalised against the firmament as the constellation Corvus. The child became so gifted in medicine it is said that he returned the departed; the serpent encircling a staff is a symbol associated with medicine.

Thus these two tales interconnect, in their attempt to plot the obscured origins of ourselves and our skies,

outlining a presence in the void,

and showing how narrative may unfold from the deepest

lacuna.

(Condos 1997: 119. Barentine, 2015: 8.

OED-Zodiac. Edelstein and Edelstein, 1998: 23. Condos, 1997: 120-121.

Eratosthenes et al., 2015: 59, 62.) 


\section{[ uncertain boundaries ]}

II.

The 'cleared site': a site that is empty of content, absent of prior constructions, and devoid of meaning. Land which lies undeveloped is perceived to be lacking any architectural context despite being littered with other, often natural, constructions. The 'constructed site': the consideration of the visible and coextensive layers of a site that have accumulated over time. The remains of agricultural production, the industrial revolution, and present operations (highways and suburban developments included). Burns argues that, as a consequence of their intertwined accumulation, these indiscrete phenomena stimulate the coincidental wonders of "interruption, simultaneity, discontinuity, synchronism, fragmentation, coincidence, and disruption": they "cohere only in abrupt juxtapositions" (Burns, 1991: 154). Yet, she acknowledges that this approach to site also misses some opportunities. As a consequence of valuing visible material only: what is absent is not considered. By using this visible material as a literal foundation upon which to construct, the resulting architecture of the site is merely an extension of the existing conditions of the location, which is itself already constructed. Therefore, the site may be seen as one appropriated rather than created by an architect: "The site is a work, a human or social trace. It is comparable to a myth, temple, or city in that it is open to archaeological deciphering. The site is a significative system with no single author" (Burns, 1991: 164). A site is never cleared, is always-already constructed, and has no unique origin.

Fig. 4 Author (2016). Craters (Asclepius meeting Earth, with trace overlay of all known non-impacts from other asteroids within the blank expanse of the universe) [Drawing]

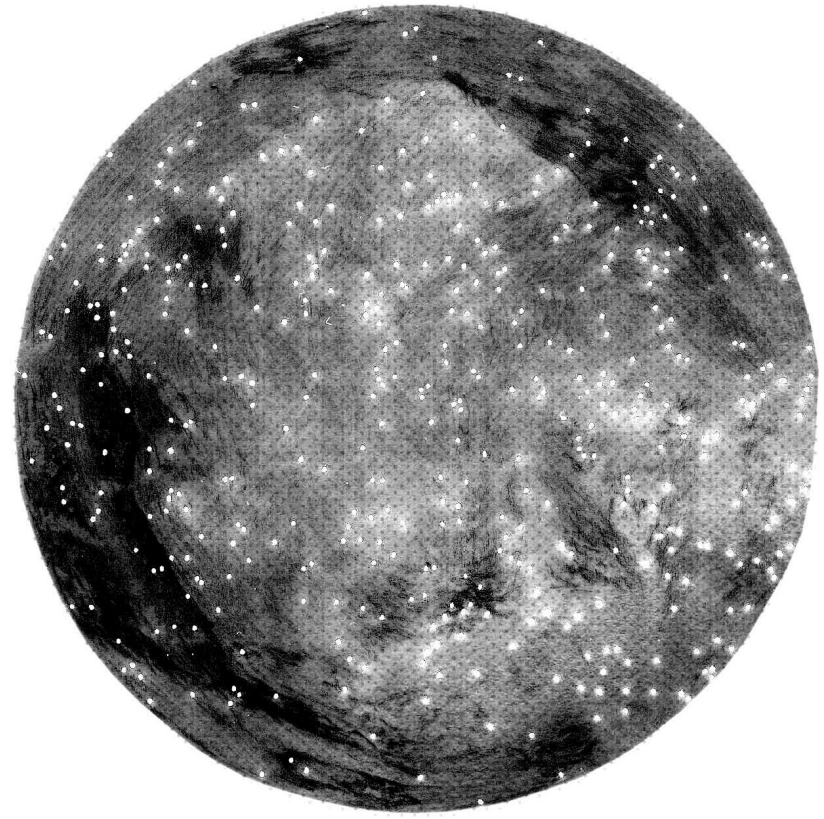




\title{
[a sounding of the cavities]
}

\author{
$I$.
}

The asteroid passed by Earth on 23 March 1989 at a distance of 0.00457AU.

It was named Asclepius.

A small asteroid of the Apollo group, it was discovered by Henry Holt from Flagstaff, Arizona (40 miles from Meteor Crater) while working on a NASA project. It is ironically named after the Greek demi-god of Healing, despite its capacity for devastation.

\section{Although the}

space between

this missile and Earth surpassed the orbital radius of the moon, the pass attracted attention, since, a few hours previous, the asteroid passed through the precise position of our planet.

The physical structure of Asclepius has never been conclusively documented;

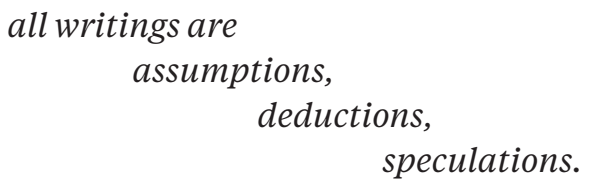

The impact may create another CRATER, devastating the encompassing environment: it may be enough to destroy a city. With oceanic impact, coastal regions may be destroyed through tsunamis. The third potential outcome of such a scenario would be non-impact, where the asteroid explodes in the Earth's atmosphere, shatters above the surface. Only through the discovery of an anomalous amount of the element Iridium on or within the ground (usually scarce within the Earth's crust) would it be

traceable,

since other meteoritic events have shown that no other fragmentary indications are left. Indeed, some impacts to this day remain contentious as a consequence of the lack of physical,

- present-

visible

evidence. 


\title{
[the absence of centre and origin]
}

\author{
II.
}

The 'cleared' and the 'constructed': neither offers a reading of site that admits the marginal, the elusive, the obscured. What is found is only the physical and evident, not the ephemeral and absent-yet-present. Traces: thin veils left behind by the absent yet present (Derrida, 2016: 68-71). In French, the word 'trace' is found to have a multitude of meanings comparable to those of its English equivalent, yet, it additionally implies definitions more closely aligned to those of the words 'track', 'path', or 'mark'. Early writing methods often involved pressing a sharp instrument into a receptive substance: the creation of a cavity within a surface (Lowe, 1993: 42-43). The impressed mark resultant from this process was a negative space, an absence, yet simultaneously, as writing, it was also a web of significations, a meaningful presence. A crater is a mark in the landscape. Its impression is resultant of the universe's quill, a text formed of the calligraphy of nature, scorched into the yielding surface of the Earth. What once existed in its place no longer does so. Often evaporating on impact, no trace is left behind of the meteorite itself. Absence. Yet, the replacement-the crater, the void-is a presence, is a trace of the event which preceded its insertion within the landscape. All marks of presence bear the traces of the absent: the crater is a mark which exists only in relation to the ground it annihilated. It dislocates, displaces, and refers beyond itself. Burns quotes Ernst Cassirer: "It is, as it were, the fundamental principle of cognition that the universal can be perceived only in the particular, while the particular can be thought of in reference to the universal" (Burns, 1991: 164). The 'craterous' site relies not on knowable parameters, but on transcendent thresholds, conscious of their ever-reaching roots and evasive inheritance.

Fig. 5 Author (2016). Craters (London, sketched figure-ground plan, with trace overlay of all known post-WWII crater locations) [Drawing]

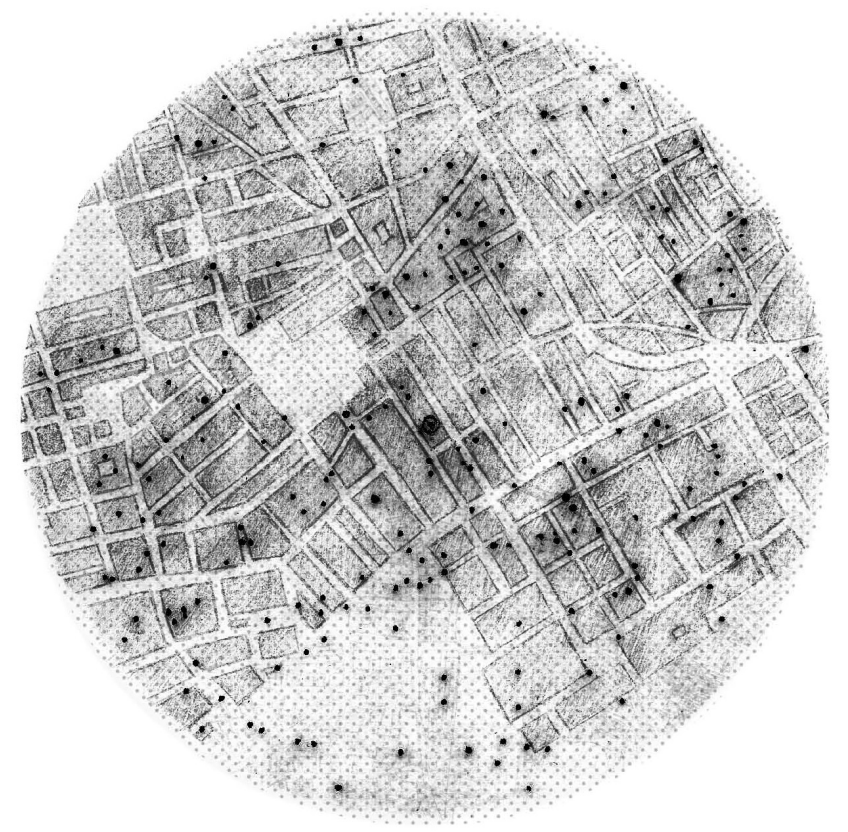




\title{
[correspondence]
}

\author{
$I$.
}

Asclepius may yet create a CRATER in our landscape.

A hole, like Meteor Crater, may open up in one of our cities.

Anonymous.

On the basis of its present orbital progression, this asteroid is unlikely to impact the Earth in the next century, or even further into the future. However, the threat of such impact has been brought to attention in the years subsequent to its discovery, with the implementation of extensive mapping of all 'near earth objects' with potential to devastate the Earth.

Yet, many remain unknown,

their trajectories not yet plotted.

A CRATER is defined as a cavity within the surface of the Earth or other heavenly body, as a bowl-shaped depression with a raised rim formed by the impact of a meteoroid. We have seen it is also a term associated with the heavens from which these potential meteorites, such as Asclepius, encircle and hurtle towards our planet.

Neverending.

Yet, it is also a descriptor for the hole or pit in the ground where a man-made device has exploded.

From Greek krater: a mixing bowl. From the root kere, to mix, confuse.

Etymological origins.

The blitzed cityscape is one confounded.

It is riddled with dead ends and plot holes that threaten memory with the blanks of forgetfulness. All that remains once the walls have fallen, are the references to them that existed beyond their physical manifestation.

The CRATER is a mixing bowl for the traces of inheritance and context:

for citations and footnotes to

other sites,

other CRATERS.

(Shoemaker et al., 1993: unpaginated. OED-crater.) 


\title{
[there are gaps through the walls]
}

\author{
II.
}

A crater is not only the calligraphy of nature. It is also the full stop of human endeavour. It is every demolition site, every cavity within the structures of our built environment. Yet, these ellipses are also pauses on the threshold between past and future construction. These holes, unlike meteor craters, are not anonymous; whether by resolution (agreement in redevelopment) or regrettable dispute (war) these holes are resultant of intention. Still, though provisional authors may be accounted for, inheritance and context may become veiled and hidden, once the cracks are papered over and the surface glossed over, to return focus from the unbearable debris and bricolage of the banlieue back to the present, visible centre of a 'space to be filled in'. Pasts are placed under erasure (Spivak, 2016: xxxvi-xxxix), nevertheless traces are always detectable, beneath the surface, in the footnotes. In post-WWII London, the problem of holes was ever-present. Mind the gap. The tabula rasa of Modernism emptied and removed, perhaps too much, but the brutality of war, equally, offered the opportunity to sweep aside the inadequate and unjust (as slum clearance programmes showed) (Bullock, 2002: 8). Throughout the war city centres were a target, and so, in anticipatory fear of future loss, industry was protected through decentralisation, moved to the outskirts of the map (Vidler, 2010: 35). Despite these clearings, the longing for the familiar, and of constructions translating the invisible (the atomic) into the quotidian, was equally profound. Thus, as Burns and Andrea Kahn have noted: "site is best viewed from points in between" (Burns and Kahn, 2005: xxiii). A space between the 'cleared' and the 'constructed', between the unknown and the familiar. An urban crater, no matter how seemingly vacant, never evades its past: it is always a space between the 'absent' and the 'present', haunted.

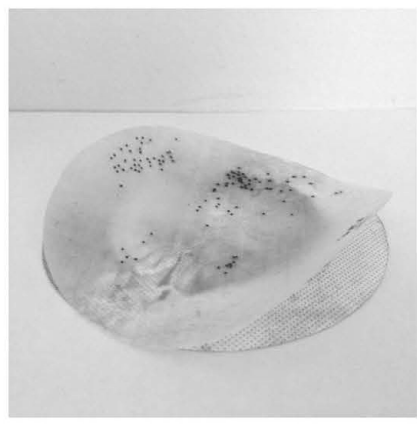

Fig. 6 Author (2016). Craters (trace layers, with spaces between) [Photograph]
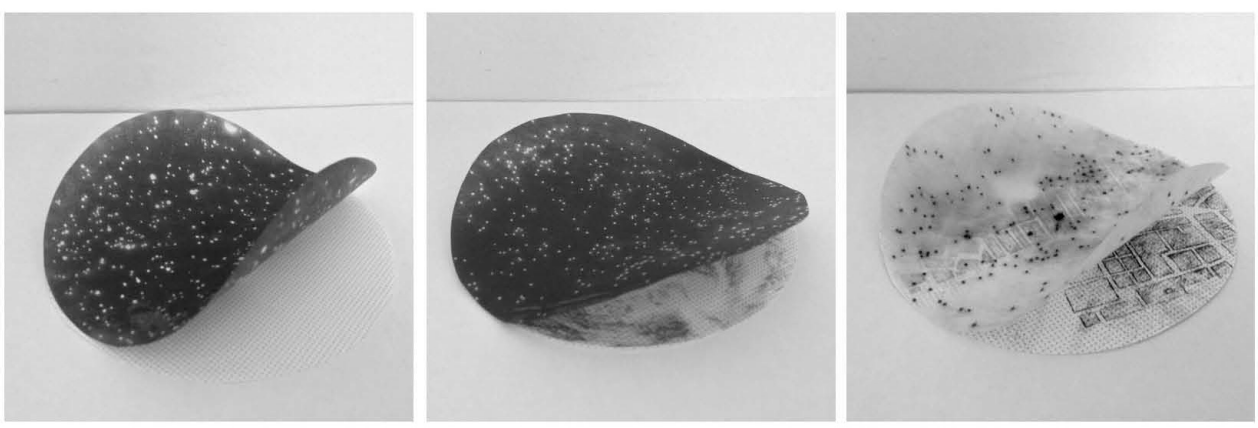


\section{[sliding through the intervals]}

$I$.

[this space is left intentionally blank...] 


\section{[speaking into the void]}

II.

As Burns observes, contemporary architectural culture is preeminently concerned with the visible, with the site as presented. There is often little regard for the over-sighted, the margins, the craters. Viewed as a synchronic phenomenon, a site becomes temporally isolated, with the historical considered and acknowledged only in relation to its influence upon the site's present, visible state. The potential to plot the temporal rather than the spatial is not pursued further (Burns, 1991: 149). The crater is not the original landscape, yet, though nothing perceptible exists, it remains a container for prior constructions, as well as for future potential. Still, it is the origin of loss and destruction for that particular location. This paper aims to highlight the invisible, the absent-yet-present: the traces disregarded, the craters circumvented. A crater is both an absence and a presence. What was there no longer is, yet, this removal forces the spatial practitioner, the decipherer of the site, to other contexts and sources of information in order to recreate the lost, the missing. It sparks a quest for recovery and reproduction, at least in understanding and figural representation (if not literal re-construction). The original is no longer the origin but may be found fragmented and dispersed: perhaps it is the destiny of all sites and situations to be shattered, scattered, and erased from view, to be found only underground, in the traces left behind within these spaces between, within these craters. 


\section{REFERENCES}

Adcock, C. E., and Turrell, J. (1990). The Roden Crater project. In James Turrell: The art of light and space. (pp. 154-207). Berkeley, California; Oxford, UK: University of California Press.

Aratus. (2010). Phaenomena (A. Poochigian, Trans.). Baltimore MD: The Johns Hopkins University Press.

Barentine, J. C. (2015). The lost constellations: A history of obsolete, extinct, or forgotten star lore. London, UK; New York, NY: Springer Praxis Books.

Barringer, D. M. (1905). Coon Mountain and its crater. Proceedings of the Academy of Natural Sciences of Philadelphia, v.57. (pp. 841-886).

Bullock, N. (2002). Building the postwar world: Modern architecture and reconstruction in Britain. London: Routledge.

Burns, C. (1991). On site:

Architectural preoccupations. In Kahn, A. (Ed.) Drawing / building/ text. (pp.146-167). New York, NY: Princeton Architectural Press.

Burns, C. and Kahn, A. (2005) Site matters: Design concepts, Histories and strategies. Oxford, UK: Routledge.

Carusi, A., Gehrels, T., Helin, E. F., Marsden, B. G., Russell, K. S., Shoemaker, C. S., Shoemaker, E. M., and Steel, D. I. (1994). Near-Earth objects: Present search programs. In Gehrels, T. (Ed.) Hazards due to comets and asteroids. (pp. 127-148). Tucson, AZ: University of Arizona Press.

Colomina, B. (2004). Unbreathed air 1956. In M. Risselada, M. and D. van den Heuvel (Eds.), Alison and Peter Smithson-from the house of the future to a house of today (pp. 30-49). Rotterdam Netherlands: 010 Publishers.

Condos, T. (1997). Hydra, crater, corvus. In Star myths of the Greeks and Romans: A sourcebook (pp. 119-123). Grand Rapids, Ml: Phanes Press.

Derrida, J. (2016). Of Grammatology (G. Spivak, Trans.). London, UK: The Johns Hopkins University Press.

Edelstein, E. J., and Edelstein, L. (1998). Asclepius: Collection and interpretation of the testimonies. Baltimore, MD: The Johns Hopkins University Press.

Eratosthenes, Hyginus, Aratus (2015). Constellation myths: with Aratus's phenomena (pp. 59-64). Oxford, UK: Oxford University Press.

Henderson, N., Paolozzi, E. Smithson, A., and Smithson, $P$. (1953). ICA memorandum, 27 March 1953. Nigel Henderson Collection, Tate Archive.

Henderson, N. (1953). Lecture notes: Parallel of life and art exhibition. Nigel Henderson Collection, Tate Archive.

Jenner, R. (1990). The spaces between. Interstices, 1 (pp.i-ii).

Lichtenstein, C., and

Schregenberger, T. (Eds.). (2001). As found: The discovery of the ordinary. Zürich: Lars Müller Publishers.

\section{Life Magazine (1948). Birth of} a solar system. Life Magazine. Vol. 24, No. 17. 26 April 1948. (pp. 91-110). Time Inc.

Life Magazine (1950). What may be biggest meteor crater is discovered. Life Magazine. Vol 29 No.7. 14 August 1950. (pp. 34-35). Time Inc.

Life Magazine (1954). 5-4-3-2-1 and the hydrogen age is upon us. Life Magazine. Vol. 36, No. 15.12 April 1954. (pp. 24-33). Time Inc.

Life Magazine (1958). The moon: myths, marvels and man's reach for it-rocket-powered quests will add to a vast store of lunar facts and fancies. Life Magazine. Vol. 45, No. 24. 15 December 1958. (pp. 89-98). Time Inc.

Lowe, W. (1993). Theology and difference: The wound of reason. Bloomington, IN: Indiana University Press.

Malraux, A. (1965). Le Musée Imaginaire. Paris: Gallimard.

Shoemaker, E. M. (1987). Meteor Crater, Arizona. Geological Society of America Centennial Field Guide-Rocky Mountain Section, 1987. (pp. 399-404).

Shoemaker, C. S., Holt, H. E., Shoemaker, E. M., Bowell, E. M. Levy, D. H. (1993). The Palomar Asteroid and Comet Survey (PACS), 1983-1993. Abstract for the IAU Symposium 160: Asteroids, Comets, Meteors 1993.
Held 14-18 June 1993, in Belgirate, Italy. Published by the Lunar and Planetary Institute, Houston, TX. p.269.

Spivak, G. C. (2016). Translator's Preface. In J. Derrida, Of Grammatology (G. Spivak, Trans.). London, UK: The Johns Hopkins University Press.

Verschuur, G. L. (1997). Impact!

The threat of comets and asteroids. Oxford, UK: Oxford University Press.

Vidler, A. (2010) Air, war and architecture. In J. Hell and A. Schönle (Eds.) Ruins of modernity. Durham; NC: Duke University Press. 